\title{
UMA ANÁLISE DA ECONOMIA COMPARTILHADA SOB O PARADIGMA DA SOLIDARIEDADE SOCIAL.
}

\author{
Sinara Lacerda Andrade ${ }^{1}$ \\ Bruno Torquete Barbosa ${ }^{2}$
}

\section{Resumo:}

O presente trabalho traçou um paralelo analítico entre e economia compartilhada e a solidariedade social enquanto propulsora das novas modalidades de desenvolvimento econômico. Para alcançar o objetivo da pesquisa, utilizou-se como referencial teórico o conceito de solidariedade de Durkheim. Como método de abordagem utilizou-se o dedutivodialético, para a análise procedimental utilizou-se o comparativo abrangendo pesquisa bibliográfica, descritiva. Elencou-se a necessidade de se buscar novos padrões de consumo e compartilhamento de bens e serviços. Analisou-se a definição do conceito: 'economia compartilhada', amparando-se em valores republicanos estampados no ordenamento constitucional que prevê a construção de uma sociedade mais equânime e solidária.

Palavras-chave: Solidariedade; Economia Compartilhada; Contexto Sociocultural

\section{AN ANALYSIS OF SHARED ECONOMY UNDER THE PARADIGM OF SOCIAL SOLIDARITY.}

\begin{abstract}
:
This paper analyzed the shared economy and social solidarity as a driver of the new modalities of economic development. To achieve the objectives, Durkheim's solidarity was used as a theoretical framework. As a method of approach we used the deductive-dialectic and for procedural analysis we used the comparative covering bibliographical, descriptive research. The need to seek new patterns of consumption and sharing of goods and services was highlighted. The concept of 'shared economy' was analyzed, based on republican values stamped in the constitution that foresees the construction of a more equitable and solidary society.
\end{abstract}

Keywords: Solidarity Shared; Economy Socio; Cultural Context

\footnotetext{
${ }^{1}$ Doutoranda e Mestre em Direito com pesquisa na linha de Empreendimentos Econômicos, Processualidade e Relações Jurídicas pela Universidade de Marília/SP (UNIMAR). Especialista em Direito Processual com ênfase em Docência do Ensino Superior pela Universidade Gama Filho, Rio de Janeiro/RJ (UGF). Bacharel em Direito pela Universidade do Estado de Minas Gerais (UEMG). Presidente da Federação Nacional dos Pós-graduandos em Direito (FEPODI). Avaliadora Associada ao Conselho Nacional de Pesquisa e Pós-graduação em Direito (CONPEDI). Professora do curso de Direito no Centro Universitário da Fundação Educacional de Barretos/SP (UNIFEB) e no Centro Universitário UNIFAFIBE de Bebedouro/SP. Conselheira na $61^{\text {a }}$ Subseção da Ordem dos Advogados do Brasil (OAB/MG). Assessora Jurídica e Advogada. E-mail: sinaralacerda.adv@ hotmail.com

${ }^{2}$ Mestre em Direito pela Universidade de Marília (2019) - Empreendimentos econômicos, desenvolvimento e mudança social. Especialização em Direito Tributário pela UNAMA-PA (2008). Graduação em Direito pela Faculdade de Direito de Varginha (2003). Alumni da Singularity University nos Estados Unidos. Professor na Uniasselvi Rondonópolis, anteriormente FAIR, desde 2.008 e UNEMAT, desde 2.018. Advogado. E-mail: torquete@hotmail.com
} 


\section{INTRODUÇÃO}

Ao se analisar sob o prisma do contexto social e cultural os novos contornos que são percebidos pela economia, torna-se imprescindível repensar novos modelos econômicos que tenderiam a servir como novos paradigmas retirando e/ou minimizando os entraves naturais que sempre se manifestam em momentos em que se discute uma mudança no contexto econômico-social.

Essa busca é inerente ao trabalho do pesquisador, uma vez que demonstrar que os próprios caminhos da sociedade culminaram em uma nova realidade, podem gerar um sentimento de naturalidade, mesmo que os resultados de certas experiências possam ser considerados por alguns como prejudiciais.

No presente estudo, apresentar-se-á inicialmente o contexto sociocultural utilizandose como referencial teórico a solidariedade social e como sistema de referência Émile Durkheim - transpassando pelas ideias de solidariedade mecânica e orgânica - que desenvolve um pensamento mais coletivista, que representaria um grau de consenso produzido entre e/ou pelos seres humanos.

Em um segundo momento, objetivar-se-á a busca pela definição do conceito de economia compartilhada que, no presente estudo, surge como forma de alternativa de se readequar a essa nova realidade social, que tem como base econômica a potencialização do que está ocioso, do compartilhamento e até da ajuda mútua.

Por tratar-se de uma análise voltado ao ordenamento jurídico, não se pretende um aprofundamento sociológico ou psicológico, pois apesar da interdisciplinaridade que o próprio tema propõe, objetiva-se justificar parcialmente o preceito constitucional da busca por uma sociedade justa e solidária.

A justificativa que ora se apresenta é entender que a função social e solidária que apresenta o paradoxo acesso x propriedade pode ser uma resposta aos anseios naturais de promoção de conjunto, e menos individualidade, numa constante busca de equilíbrio.

Como método de abordagem utilizar-se-á o dedutivo-dialético. Para a análise procedimental utilizar-se-á o método comparativo abrangendo pesquisa bibliográfica, descritiva. Analisar-se-á casos concretos, que servirão como protótipos, como forma de alcançar os resultados propostos. 
Apresentar-se-á o contexto que promove esse coletivismo e também demonstrar-se-á que - mesmo havendo o sentimento restrito ao grupo - o pensamento solidário já era observado em comunidades nativas, que não sofreram o impacto nocivo dos da incorporação da globalização cultural, demonstrando que a solidariedade social tornar-se-á o meio mais efetivo para a construção de uma sociedade mais equânime e justa.

\section{A SOLIDARIEDADE NO CONTEXTO SOCIOCULTURAL}

Qualquer observação para que possa ser transmitida, faz-se necessário que se apresente o ângulo de partida, uma vez que outros pesquisadores que debrucem sobre o tema somente poderão ter a mesma visão se a observação for no mesmo sentido.

Atualmente partindo-se pelo que noticiam os veículos midiáticos é apresentado por lideranças políticas, interesses diversos e até por estudiosos, um ambiente global desestimulante no que se refere aos recursos postos à disposição da vida. Essa realidade de escassez, pelo menos à grande parte da população é ampliada pela crescente desigualdade social, concentração de renda, mudanças climáticas e descaso com degradação ambiental.

Ocorre que, se o olhar estiver fixo no futuro, a observação sempre terá essa limitação, sendo evidente, que pode ser bastante educativo que o ponto de observação seja de certa forma recuado ao passado.

Peter H. Diamands e Steven Kotler (2012), elucidam que se vive uma época turbulenta e constata-se isso lendo os noticiários que já é suficiente para deixar qualquer um preocupado, e - com o fluxo incessante de mídia tornou-se muito difícil se afastar dessas notícias, bem como, segregá-las entre fidedignas ou não.

A evolução moldou o cérebro humano para ter uma consciência aguda dos perigos potenciais, essa nefasta combinação exerce um impacto profundo na percepção humana: ela literalmente bloqueia nossa capacidade de assimilar boas novas. Isso cria um desafio para nós, já que abundância é uma história otimista. Devemos examinar os fatos objetivos, a ciência e a engenharia, as tendências sociais e as forças econômicas que vêm rapidamente transformando nosso mundo. Mas não podemos ser tão ingênuos a ponto de achar que não haverá obstáculos ao longo do caminho. Alguns serão grandes obstáculos: crises econômicas, desastres naturais, ataques terroristas. Durante esses períodos, o conceito de abundância parecerá distante, 
estranho, até absurdo, mas uma breve observação da história mostra que o progresso continua através das épocas boas e ruins.

Os autores prosseguem elucidando que:

\begin{abstract}
O século 20, por exemplo, testemunhou avanços incríveis e tragédias indizíveis. A epidemia de gripe de 1918 matou 50 milhões de pessoas. A Segunda Guerra Mundial matou outras 60 milhões. Ocorreram tsunamis, furacões, terremotos, incêndios, inundações, até pragas de gafanhotos. Apesar dessas perturbações, esse período também viu a mortalidade infantil cair $90 \%$, a mortalidade materna cair $99 \%$ e, no todo, a expectativa de vida humana aumentar mais de $100 \%$. Nas duas últimas décadas, todos os países experimentaram enormes distúrbios econômicos. Mesmo assim, hoje em dia até os mais pobres têm acesso ao telefone, à televisão e a vasos sanitários com descarga - três luxos que nem os mais ricos podiam imaginar na virada do último século. Na verdade, como logo ficará claro, por quaisquer parâmetros disponíveis, a qualidade de vida melhorou mais no último século do que em qualquer outra época. Assim, ainda que ocorram muitas interrupções violentas e angustiantes ao longo do caminho, os padrões de vida globais continuarão melhorando, independentemente dos horrores que dominarem as manchetes. (DIAMANDS e KOTLER, 2012, p. 07)
\end{abstract}

Partindo desse ponto é possível que o futuro não seja necessariamente um cenário de escassez, é possível que se abra espaço para novas modalidades de economia e consumo que tenham no compartilhamento, colaboração e solidariedade suas principais bases.

Contraponto ao crescimento individualizado do ser e a desigualdade nas oportunidades, "as representações, as emoções e as tendências coletivas não têm como causas geradoras certos estados de consciência individual, mas as condições em que se encontra o corpo social em seu conjunto." (Durkheim, 2001, p.67)

Surge um novo capitalismo no século XXI, animado por uma redução radical nos custos de coordenação numa variedade impressionante de atividades humanas. A colaboração no mercado chegará a níveis inéditos, privilegiando o acesso compartilhado em detrimento da propriedade pura e simples. O capitalismo se reinventa valorizando uma nova forma de coletivismo. Torna-se possível a partir de agora um novo modelo de relacionamento humano onde a cooperação livre e a criatividade responsável têm o potencial de formar o núcleo de um novo paradigma de criação de riqueza. (GANKY, 2011, p. XV)

Para Durkheim (1989, p.45), a consciência coletiva distingue-se dos estados de consciência individual, pois é produto de uma imensa cooperação que se estende não apenas no espaço, mas no tempo e que só pôde se constituir por meio de uma multidão de espíritos diversos que, associados, misturados e combinados em ideias e sentimentos, ao longo de gerações, originaram "uma intelectualidade mais rica e mais complexa que a do indivíduo. 
Dessa proposição decorre a tese de que a sociedade é superior aos indivíduos, pois está investida de uma autoridade moral que sempre se afigurou aos homens e da qual eles não podem se separar sem correr o risco de perder a melhor parte de si mesmos: sua condição humana. (Durkheim, 1978, p.45)

Mesmo considerando que a intensificação da divisão do trabalho nas sociedades modernas implicou a substituição da "solidariedade mecânica" pela "solidariedade orgânica", dirimindo o peso exercido pelas antigas formas de organização social e alargando o campo de atuação do indivíduo, o "individualismo moral", segundo (Durkheim, 2008, p.50), não seria capaz de resguardar a vida coletiva, pois seu avanço constituiria uma ameaça à vida social.

Em que pese o ambiente aparentemente propício há que se refletir sobre as possíveis resistências sociais:

\footnotetext{
O empecilho, contudo, é que, tenha ou não sido moldado pelas decisões de nossos ancestrais, nosso mundo de começo do século XXI não é favorável a uma coexistência pacífica, e muito menos à solidariedade humana e à cooperação amigável. Ele foi moldado de tal forma que torna a cooperação e a solidariedade não apenas uma escolha impopular, como também difícil e onerosa, e em relativamente poucas ocasiões, considerem que esteja em seu poder material e/ou espiritual fazer essa opção e deslindar seu verdadeiro sentido. (BAUMAN, 2015, p. 37)
}

Em que pese o paradoxo acima apresentado surge uma nova classe de empreendimentos que crescem exponencialmente mesmo considerando uma desnecessidade de estruturas aparentemente essenciais.

É como um restaurante sem cozinha, ou uma empresa aérea sem aeronaves, parece inimaginável uma empresa de transporte privado de pessoas sem carros próprios ou motoristas em seu quadro de colaboradores, uma empresa que hospeda pessoas mas não dispõe de hotéis, quartos ou camas, ou ainda quem se proponha a empreender no ramo de comunicação sem possuir cabos, satélites, torres, sinais de rádio ou nem mesmo aparelhos de telefonia.

Para se obter respostas para os questionamentos acima, basta observar que existem empresas com esse propósito, mas que além de serem possíveis, lideram os seus mercados, como é o caso da iFood, UBER, AirBnB e WhatsApp. 
A observação de tais empresas atuando em um nicho específico, mas promovendo mudanças sociais que vão muito além de suas pretensões iniciais, como no caso do UBER que inclusive juridicamente e socialmente gerou termos como "uberismo"33 e "uberização". 4

Termo utilizado para essa quebra de padrão dos empreendimentos, "disrupção", tem por sinônimos: ruptura, rompimento, fratura. Valendo trazer seu verbete constante do Dicionário Michaelis da Língua Portuguesa: “Ato ou efeito de romper(-se); disrupção, fratura."

Uma modernidade leve surge em contraponto à pesada outrora existente: "Essa parte da história, que agora chega ao fim, poderia ser chamada de, na falta de nome melhor, de era do hardware, ou modernidade pesada" (BAUMAN, 2001, p. 144)

[...] a passagem da fase "sólida" da modernidade para a "líquida" - ou seja, para uma
condição em que as organizações sociais (estruturas que limitam as escolhas
individuais, instituições que asseguram a repetição de rotinas, padrões de
comportamento aceitável) não podem mais manter sua forma por muito tempo (nem
se espera que o façam), pois se decompõem e se dissolvem mais rápido que o tempo
que leva para moldá-las e, uma vez reorganizadas, para que se estabeleçam. É pouco
provável que essas formas, quer já presentes ou apenas vislumbradas, tenham tempo
suficiente para se estabelecer, e elas não podem servir como arcabouços de
referência para as ações humanas, assim como para as estratégias existenciais a
longo prazo, em razão de sua expectativa de vida curta: com efeito, uma expectativa
mais curta que o tempo que leva para desenvolver uma estratégia coesa e
consistente, e ainda mais curta que o necessário para a realização de um "projeto de
vida" individual. (BAUMAN, 2007, p. 07)

E esse é o ambiente em que se desenvolve essa moderna economia, pois: "O tempo instantâneo e sem substância do mundo do software é também um tempo sem consequências" (BAUMAN, 2001, p. 150). Provavelmente esta ruptura social promova o desapego material que alavanca pretensões coletivas ou colaborativas.

\section{PERSPECTIVAS DA ECONOMIA COMPARTILHADA}

\footnotetext{
${ }^{3}$ Termo utilizado na sentença do processo n. 0011359-34.2016.5.03.0112. BRASIL. Tribunal Regional do Trabalho $\quad 3^{\mathrm{a}} \quad$ Região. $\quad$ RTOrd. $\quad \mathbf{n}^{\mathbf{0}}$ 0011359-34.2016.5.03.0112. Disponível em: http://pje.trt3.jus.br/primeirograu/Processo/ConsultaDocumento/listView.seam?nd=17013114275439000000038 127039. Acesso em: 20 out. 2019

4 Léxicos que definem modelos de negócio que se utilizam da economia compartilhada. Disponível em: http://economiadocompartilhamento.com.br/o-que-e-uberizacao. Acesso em: 20 out. 2019

${ }^{5}$ Dicionário da Língua portuguesa Michaelis. 'Disrupção'. Publicado em: 08 maio de 2017. Michaelis on-line. Disponível em: http://michaelis.uol.com.br/busca? $\mathrm{r}=0 \& \mathrm{f}=0 \& \mathrm{t}=0 \&$ palavra=disrup\%C3\%A7\%C3\%A3o. Acesso em: 20 maio de 2019.
} 
O conceito de Solidariedade também possui sua genealogia no ordenamento jurídico, mas se destaca como será a seguinte apresentado como uma essência do ser, que gera um ambiente favorável para novas modalidades econômicas que não podem estar atreladas a padrões estabelecidos no individualismo.

Importante destacar que a ideia de capital é muito anterior ao capitalismo (SINGER, 1993) e que muitos conceitos de trocas que hoje fundamentam parte da suposta novidade denominada de economia compartilhada já se encontravam presentes nas trocas mercantis da idade média.

Ora, impõe-se observar que não raras vezes o compartilhamento pode ser interpretado como uma forma de crescimento:

\begin{abstract}
Nos últimos dois séculos, a economia industrial recompensou um tipo de específico de capitalista. Sobreviver e prosperar envolvia se tornar só um pouquinho menor que um monopólio, controlando o mercado ao mesmo tempo em que evitada a regulamentação. $\mathrm{O}$ controle ela mantido pela detenção exclusiva de propriedade intelectual, segredos comerciais, direito autorais, equipamentos e funcionários. Por quê? Porque fábricas, ferramentas e outros meios dispendiosos de produção exigiam organizações grandes o suficiente para extrair todo o seu potencial. Produtos e serviços eram padronizados porque grandes volumes levavam a economias de escala e a capacidade de oferecer produtos a preços mais baixos. Maiores volumes também traduziam em uma maior participação de mercado. E de repente a internet entra na equação. Aquelas velhas barreiras à entrada - grandes ativos de capital fechado e propriedade intelectual fechada - deixam de resultar no maior valor. Acabam sendo estratégias datadas, incapazes de corresponder ao potencial encontrado nos ativos compartilhados, que sempre oferecerão retornos melhores e colocarão o poder nas mãos de multidões que representam pools intelectuais infinitamente maiores. Assim, no mundo todo, o poder está passando de entidades morosas, fechadas e centralizadas ao modelo da Peers Inc, ágil, adaptável e distribuído. É assim que as organizações da Peers Inc começam a reinventar o capitalismo." (CHASE, 2015, p.288)
\end{abstract}

Questões que estimulam o pensamento solidário, também podem ser observadas em território nacional. É fato que o Brasil vem se estruturando para fazer frente às demandas da nova economia. Em julho, por exemplo a Comissão de Valores Mobiliários (CVM) publicou a norma 5886 que regula e incrementa o financiamento coletivo equity crowdfunding. A ideia é oferecer segurança e regras claras para captar recursos para bons projetos.” (BULL, 2017, p. 22)

\footnotetext{
${ }^{6}$ Instrução CVM 588. Dispõe sobre a oferta pública de distribuição de valores mobiliários de emissão de sociedades empresárias de pequeno porte realizada com dispensa de registro por meio de plataforma eletrônica de investimento participativo e altera dispositivos. Disponível em: www.cvm.gov.br/legislacao/instrucoes/inst588.html. Acesso em: 13 de ago. 2019
} 
Tais questões em que pesem poder levar a diferentes conceitos econômicos, como por exemplo a possível diferenciação entre economia solidária, colaborativa e compartilhada, não afastam uma origem comum, em que pese Bauman também apresentar um contraponto, ancorado em uma possível resistência social:

\begin{abstract}
O empecilho, contudo, é que, tenha ou não sido moldado pelas decisões de nossos ancestrais, nosso mundo de começo do século XXI não é favorável a uma coexistência pacífica, e muito menos à solidariedade humana e à cooperação amigável. Ele foi moldado de tal forma que torna a cooperação e a solidariedade não apenas uma escolha impopular, como também difícil e onerosa, e em relativamente poucas ocasiões, considerem que esteja em seu poder material e/ou espiritual fazer essa opção e deslindar seu verdadeiro sentido. (BAUMAN, 2015, p.37)
\end{abstract}

Apesar do contraponto, o próprio autor apresenta o contexto que ora se busca quando ensina que: "Essa parte da história, que agora chega ao fim, poderia ser chamada de, na falta de nome melhor, de era do hardware, ou modernidade pesada" (BAUMAN, 2001, p.144), e em obra mais recente:

[...] a passagem da fase "sólida" da modernidade para a "líquida" - ou seja, para uma condição em que as organizações sociais (estruturas que limitam as escolhas individuais, instituições que asseguram a repetição de rotinas, padrões de comportamento aceitável) não podem mais manter sua forma por muito tempo (nem se espera que o façam), pois se decompõem e se dissolvem mais rápido que o tempo que leva para moldá-las e, uma vez reorganizadas, para que se estabeleçam. É pouco provável que essas formas, quer já presentes ou apenas vislumbradas, tenham tempo suficiente para se estabelecer, e elas não podem servir como arcabouços de referência para as ações humanas, assim como para as estratégias existenciais a longo prazo, em razão de sua expectativa de vida curta: com efeito, uma expectativa mais curta que o tempo que leva para desenvolver uma estratégia coesa e consistente, e ainda mais curta que o necessário para a realização de um "projeto de vida" individual. (BAUMAN, 2007, p.07)

Tal realidade há que ser absorvida por quem deseja empreender nessa dinâmica que tem o compartilhamento como tônica as empresas capazes de engajar seus stakeholders em uma visão clara do futuro compartilhado e de atuar de forma superior em relação aos seus concorrentes no sentido dos três pilares estarão muito melhor posicionadas para conquistar as mentes e os corações das pessoas - como também o dinheiro. (ELKINGTON, 2012, p. 73)

Surgem empreendimentos que crescem, como já dito, em um cenário que desafia a própria estrutura, pois estruturar como modelo de negócio o transporte de pessoas, sem o elemento meio de transporte integrado à estrutura, ou hospedaria sem o local adequado para tal, indubitavelmente em outros tempos se caracterizaria como uma insanidade. 
Nesse contexto nascem diversas possibilidades, tendo a colaboração, que advém como apresentado da solidariedade, como premissa. Termos como crowdfunding, o coworking, o colinving, crowdsource, etc. A sociedade se organiza em rede a reputação passa a ser paradigma das relações, e a voz que antes não era ouvida se apresenta ao mundo.

\begin{abstract}
Atuando dentro de um novo espaço (ciberespaço) e de um novo paradigma (rede), a sociedade civil organizada, em suas diversas formas, promove novos tipos de ações coletivas, gerando novas formas de ativismo e de empoderamento por meio de articulações em rede e participação política (e-participação) (ARAÚJO et al., 2015, p. 1598).
\end{abstract}

Destaca-se que o compartilhamento não encontra barreiras, é quando se busca limitações provavelmente a primeira que se aponta é o compartilhamento de recursos financeiros, entretanto, dentre as modalidades que ora se enquadra no conceito de economia compartilhada, ora em outras modalidades, é o crowdfunding, que em linhas gerais "nada mais é do que utilizar sua rede social digital para, através da divulgação também digital do seu projeto, pedir doações em troca de prêmios para pessoas que gostariam que o objetivo fosse alcançado. (CARNEIRO, 2014, p. 15), fortalece a ideia, e com o advento das redes sociais recebem um incremento que não se pode ignorar.

O Facebook é um exemplo. Um dos seus fundadores, Chris Hughes, diferentemente dos seus sócios, Mark Zuckerberg e Dustin Moskivitz, declarou que nunca esteve interessado no software em si, mas em descobrir como as pessoas poderiam se conectar e compartilhar coisa umas com as outras e como uma comunidade online poderia enriquecer as vidas dos seus usuários Hughes saiu do Facebook em fevereiro de 2007, no início da sua grande expansão, com mais de 10 (dez) milhões de usuários ativos, para liderar a, na época, despretensiosa campanha online de Barack Obama à presidência dos Estados Unidos da América, por acreditar na crença de Obama na forma coletiva (BOTSMAN; ROGERS, 2011, pp. 43-44 apud SANTIAGO, CAMPELLO, 2016, p. 149).

A questão que se apresenta como meio de permear tais questões é o paradigma propriedade $X$ acesso. Não raras vezes, buscando um serviço, uma função, o indivíduo vê-se obrigado a adquirir um produto, exemplos como a escada e a furadeira são os clássicos, a não ser quem tem tais ferramentas como meios de desempenhar suas atividades laborais, parece claro que o indivíduo que não exerce tais funções na verdade quer apenas um furo na parede ou alcançar um objeto alto, e não se ver obrigado a desembolsar grandes somas e ainda ter 
que disponibilizar espaço para armazenar itens que podem não chegar a ser utilizados durante uma hora, no decorrer de anos.

As relações entre produtos físicos, propriedade individual e personalizada, estão passando por uma profunda evolução. Não queremos o CD; Queremos a música que toca. Nós não queremos o disco. Queremos o armazenamento. Nós não queremos a secretária eletrônica; Queremos as mensagens armazenadas. Nós não queremos o DVD; Queremos o filme. Em outras palavras, queremos não o material, mas as necessidades ou experiências que ele nos proporciona. ${ }^{7}$ (BOTSMAN e ROGERS, 2011, p. 97)

A correlação entre acesso e propriedade está posta, busca-se o crowdfunding como meio angariar financiamento de forma não convencional, e na tônica dessa nova economia o crowdsourcing e o coworking acima citadas merecem seus destaques, como bem lembra DIAMANDS e KOTLER, buscando exemplificar tais possibilidades:

\begin{abstract}
Começou no final dos anos 2000. Matt Barrie estava irritado. Um capitalista de risco e empresário com experiência em segurança da informação, Barrie estava codificando um site e tentando contratar alguém - qualquer pessoa - para fazer alguma entrada básica de dados. Suas propostas eram decentes. Ele estava disposto a pagar dois dólares por linha para o irmãozinho ou irmãzinha de um amigo. Mas havia aulas de futebol, provas. Todo o processo foi se arrastando por meses, e não estava funcionando. "Frustrado", diz Barrie, "fiquei online e postei o emprego em um site chamado 'Get a Freelancer'. Três horas depois, voltei ao meu computador e encontrei setenta e quatro e-mails de pessoas dispostas a fazê-lo em qualquer lugar, de cem dólares a mil. Contratei uma equipe no Vietnã que terminou o trabalho em três dias. Foi perfeito. Eu não tinha que pagar até que tudo estivesse pronto. Todo o processo foi impressionante. $^{8}$ (DIAMANDIS, e KOTLER 2016, p.149)
\end{abstract}

Paul Singer busca definir o que seria essa economia que ora se apresenta como um conjunto de experiências coletivas de trabalho, produção, comercialização e crédito,

\footnotetext{
${ }^{7}$ The relations between physical products, individual ownership and self-identity is undergoing a profound evolution. We don't want the CD; we want the music it play's. We don't want the disc. We want the storage it holds. We don't want the answering machine; we want the messages it saves. We don't want the DVD; we want the film it carries. In other words, we want not the stuff but the needs or experiences it fulfils.

${ }^{8}$ It started in the late 2000s. Matt Barrie was irritated. A venture capitalist and entrepreneur with expertise in information security, Barrie was coding a website and trying to hire someone-anyone-to do some basic data entry. His rates were decent. He was willing to pay two dollars a line to the kid brother or kid sister of a friend. But there was soccer practice. There were exams. The whole process dragged on for months. It wasn't working at all.

"In frustration" says Barrie, "I got online e posted the job on a site called Get a Freelancer. Three hours later, I came back to my computer and found seventy-four emails from people willing to do it for anywhere from a hundred dollars to a thousand. I hired a team in Vietnam that finished the job in three days. It was perfect. I didn't have to pay them until everything was done. The whole process was mind-blowing.
} 
organizadas por princípios solidários e que aparecem sob diversas formas: cooperativas e associação de produtores, empresas autogestionárias, bancos comunitários, clubes de troca, e diversas organizações populares urbanas e rurais (SINGER; SOUZA, 2000, p. 123)

A cultura da sociedade deve acompanhe estas novidades pois, são estas ferramentas que nos ligam em rede, e fazem surgir novas oportunidade de compartilhamento do que antes não se imaginava compartilhável. (SHIRKY, 2011 p. 129)

Claramente sempre haverá contrapontos, e ao se deparar com essa nova economia, pode-se estar diante novamente da pergunta de Bauman "se a Riqueza de poucos realmente beneficiaria a todos", Arun Sundararajan, tecendo sua obra sobre tal modelo econômico, alerta:

\begin{abstract}
Estamos indo em direção a uma economia em que muitos acabarão por privilegiar apenas alguns? E se essa eficiência do capitalismo baseado na multidão levar a uma economia que dependa cada vez mais de plataformas peer-to-peer para organizar a atividade econômica, como teremos fornecedores sob demanda de uma rede de segurança social - seguro de saúde, trabalhador seguro, férias pagas, licença de maternidade? Precisamos de um sistema básico renda? Ou há algum novo modelo de parceria público-privado inteligente que pode fazer Benefícios portáteis e estabilizar

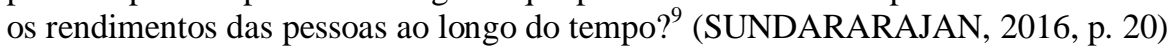

Possivelmente a humanidade se verá diante de uma necessidade de universalizar uma renda básica, entretanto para que se tenha ambiente para tal proposta, as bases da solidariedade precisam estar efetivamente demonstradas e presentes.

Observa-se que a proposta de Universal Basic Income já é realidade na Finlândia ${ }^{10}$, mas não se trata de um conceito novo, uma vez que há 500 anos vem sendo discutido, antes evidentemente de forma utópica, mas tendo como seu principal pensador o Filósofo Tomas More $^{11}$, coincidentemente ou não sua principal obra leva o nome de Utopia.

\footnotetext{
${ }^{9}$ Are we heading toward an economy in which the on-demand many serve the privileged few? And if the efficiencies of crowd-based capitalism lead to an economy that relies increasingly on peer-to-peer platforms to organize economic activity, how do we supply its on-demand providers with a social safety net-health insurance, worker's insurance, paid vacations, maternity leave? Do we need a government-provided basic income? Or is there some clever new public-private partnership model that can make benefits portable and stabilize people's incomes over time?

10 World Economy. One year on: Is Finland's free money experiment working? Disponível em: https://www.cnbc.com/2018/01/01/one-year-on-finland-universal-basic-income-experiment.html. Acesso em: 08 ago. 2019

${ }^{11}$ Thomas More, Thomas Morus ou Tomás Moro (Londres, 7 de fevereiro de 1478. Londres, 6 de julho de 1535) foi filósofo, homem de estado, diplomata, escritor, advogado e homem de leis, ocupou vários cargos públicos, e em especial, de 1529 a 1532, o cargo de "Lord Chancellor" (Chanceler do Reino - o primeiro leigo em vários
} 
Há que se observar que o compartilhamento serve para conectar pessoas através de bens e serviços gerando valor econômico para os envolvidos, otimização de tempo, e flexibilidade nos negócios (BELK, 2013, p. 5).

Além do sentido prático e econômico, novos conceitos de consumo beneficiam o meio ambiente e a comunidade em si, em que pese as preocupações claramente justificáveis, o pensamento coletivista pode ser considerado como natural ao ser, com se verá a seguir.

\section{A SOLIDARIEDADE COMO ELEMENTO SOCIOCULTURAL}

É imperioso que, ao se tratar do tema solidariedade não seja imposto o limite de ser uma análise comportamental, de seres que alcançaram uma maior instrução e por tais razões possuem um conceito mais abrangente de humanidade.

Evidentemente que a generalização é um risco constante, entretanto o que se observa, apenas a título de exemplo é que esse não é um caminho garantido, pois, facilmente se encontra indivíduos que a instrução formal se consubstancia em uma bolha existencial que ao invés de ampliar a visão passa a se comportar como um entrave à percepção do outro.

Esse individualismo pode ser justificado por uma busca pela sobrevivência, entretanto há que se observar que, em que pese a ideia da sobrevivência possa também estar atrelada ao contexto cultural/educacional, mas nesse aspecto à correlação natural é ainda mais profunda, uma vez que tal inclinação para a autopreservação é fator que nos iguala aos seres tidos por irracionais.

Essa perversa realidade também pode ser constatada em ambientes que por sua natureza deveriam primar exatamente pelo pensamento inclusivo, mas onde não raras vezes impera o individualismo, que é o ambiente político. Na busca pelo poder, algo que também há quem defenda ser natural ao ser humano, faz com que o interesse individual suplante o coletivo por mais que as pretensões das legislações sigam em sentido contrário.

Apenas para enfatizar o não necessário caminhar de mãos dadas do avanço na educação formal com o pensamento não individual, pode-se também levantar a hipótese que a especialização em um tema restringe até o convívio em grupo a medida de que se aprofunda.

séculos) de Henrique VIII da Inglaterra. É $\quad$ geralmente considerado como um dos grandes humanistas do Renascimento. Sua principal obra literária é Utopia 
Como meio de ilustrar a questão, ora apresentada, há que se trazer o exemplo de Maria Antonieta $^{12}$, que acabou por vivenciar, merecendo ou não, um triste fim ${ }^{13}$, conta-se que ao ser interpelada pela afirmação de que o "povo não tem pão" numa famosa resposta que demonstra a dificuldade de se enxergar além do meio que está-se inserido, sugeriu que o povo "comesse brioches". Sempre cabendo dar a tão folclórico personagem o benefício da dúvida uma vez que não se pode assegurar a veracidade da frase, em que pese tendo em vista os relatos que cercam sua vida, essa figura história consubstancia a ilustração adequada.

$\mathrm{O}$ que se pretende, em que pese o contraponto necessário, é demonstrar que o pensamento coletivo pode ser algo natural, inato do ser humano e para isso trazemos como exemplos comunidades primitivas ou nativas, dependendo referencial.

Em estudo político/sociológico recente, Eduardo Matarazzo Suplicy apresentou obra em que pretendendo justificar seu projeto, enquanto senador da república da Renda Básica de Cidadania, o que diga-se de passagem não se trata de matéria inédita no cenário político mundial, mas que ganha importância no presente estudo quando o autor nos oferta uma análise de povos indígenas:

A propriedade da terra na sociedade indígena é de todos, e entre eles não há patrões nem empregados. Para ter o direito de usufruir a terra, é preciso apenas haver laços étnicos e de parentesco. A produção não é coletiva, mas comunitária, caracterizada pela cooperação de grupos familiares em todas as tarefas, como as de derrubada, queima, plantio e colheita, ou caça, com troca de trabalho e bens, baseada no sistema de parentesco." (SUPLICY, 2013, P. 143)

Mesmo que a princípio o autor possa ainda assim se referir à comportamentos de uma mesma etnia ou até de uma família, e não do comportamento determinante, cumpre ainda assim socorrer-se do mesmo estudo que assim continua:

12 Maria Antônia Josefa Joana de Habsburgo-Lorena (em alemão: Maria Antonia Josepha Johanna von Habsburg-Lothringen; francês: Marie Antoinette Josèphe Jeanne de Habsbourg-Lorraine) (Viena, 2 de novembro de 1755 - Paris, 16 de outubro de 1793) foi uma arquiduquesa da Áustria e rainha consorte da França e Navarra. Décima quinta e penúltima filha de Francisco I do Sacro Império Romano-Germânico, e da imperatriz Maria Teresa da Áustria, casou-se em abril de 1770, aos quatorze anos de idade, com o então delfim de França (que subiria ao trono em maio de 1774 com o título de Luís XVI), numa tentativa de estreitar os laços entre os dois inimigos históricos. Disponível em: https://pt.wikipedia.org/wiki/Maria_Antonieta. Acesso em: 18 ago. 2019.

${ }^{13}$ Executada ao meio dia de quarta-feira, 16 de Outubro de 1793, entre os brados de uma multidão eufórica, Maria Antonieta de Habsburgo-Lorena tornara-se uma espécie de não-ser depois de sua morte. Disponível em: https://rainhastragicas.com/2013/10/17/julgamento-e-morte-de-maria-antonieta-a-ultima-rainha-da-franca-parteiv. Acesso em: 18 ago. 2019 
A chave da sociedade indígena é a reciprocidade, não o coletivo. Todas as retribuições são bem-vindas, mesmo que pequenas. O produtivismo não é a diretriz - os pequenos bocados são apreciados. Daí a flexibilidade nos horários para produzir, dormir ou comer, sem rigidez alguma." (SUPLICY, 2013, P. 144)

Assim, não se pode classificar como perfeita organização social, mas o destaque que se busca é a solidariedade como marca natural do ser humano, não relacionada essencialmente à formação, cultura ou educação em geral, como já tratado.

Morin reforça tais questões quando elenca as referidas características em povos nativos. Elucidando que essas sociedades se constituem de modelos fechados de solidariedade comunitária. Onde não existe individualismo à maneira ocidental, ali cada indivíduo realiza plenamente o emprego de suas aptidões sensoriais - visão, audição, olfato, tato. Todos são "policompetentes," tendo como exemplo o homem entalha seus instrumentos, fabrica suas armas e projéteis, encontra a caça, persegue-a e abatê-a. A mulher se ocupa das crianças, junta forragem para os animais e os vegetais para a alimentação, cozinha, confecciona cerâmica, tecidos, objetos preciosos.

Para o autor, em nosso mundo ocidentalizado, o desenvolvimento das técnicas e das especializações "atrofiou as aptidões sensoriais e inibiu as potencialidades em policompetências, que não são mais realizadas senão pelos destituídos das favelas da África e pelos Artesãos”. (MORIN, 2005, P. 93)

Como se pode observar mesmo em uma análise interna a marca do pensamento coletivo está presente, e antes que se questione que tal traço apenas esteja ligado à laços étnicos ou sanguíneos há que se observar que a análise de tais comunidades sob o prisma da realidade de quem facilmente se comunica, se informa de outras culturas e porque não dizer consegue ter uma visão globalizante não pode ser aplicar haja vista tais comunidades nativas terem características até de completo isolamento que inclusive pode ser involuntário, ou até natural, se considerados os povos nativos de algum lugar específico, que não necessariamente possuem qualquer interação com outros povos próximos.

É importante ainda destacar o trabalho do autor acima citado, quando conclui o pensamento retro apresentado ensinado que:

Não podemos nos limitar a recensear as qualidades das civilizações adquiridas principalmente pelas sociedades europeias, pois por outro lado, seria necessário recensear também as qualidade de solidariedade e de comunidades perdidas, sem 
mencionar as barbáries e crueldades sobre as quais nossas civilizações se fundaram e desenvolveram e que prosseguem com o aniquilamento cultural e físico da humanidade nativa." (MORIN, 2005, P. 94)

Assim, afim de buscar apresentar como hipótese a característica do pensamento coletivo como marca natural do ser humano, trazer à análise tais exemplos, em que pese haver a cultura própria respectiva de cada povo, pode significar base sólida para aduzir que sem o que podemos chamar de bloqueios culturais a tal modo de vida, o ser humano por ser tido como, não necessariamente e não naturalmente individualista. O que também acaba por concluir o autor quando entende que: "Existe em cada um e em todos um potencial de solidariedade." (MORIN, 2015, p.77)

Por tais razões, em que pese em desafios para que tal inclinação natural possa se apresentar de forma mais explícita em uma sociedade que pontualmente não estimula esse comportamento, há o que se pode chamar de inspirações até normativas para que a humanidade se desprenda de bolhas que não conduzem à um bem comum.

Cumpre a fim de reforçar a proposta trazer parte do preambulo da Declaração Universal dos Direitos Humanos, que pretende enquadrar os seres como membros de uma mesma família, o que resulta em outra dimensão da Solidariedade, que é a Fraternidade, considerando que o reconhecimento da dignidade inerente a todos os membros da família humana e de seus direitos iguais e inalienáveis é o fundamento da liberdade, da justiça e da paz no mundo.

Tendo sido a Solidariedade apresentada como algo natural, e justificada por exemplos de sociedades nativas, a questão sanguínea ou étnica que pode ser usada como justificativa ao não enquadramento de tal comportamento natural ao ser destinado à membro externo, acaba também sendo descartada quando suprida pela ideia de fraternidade que traz todos os povos para a mesma "casa".

Cumpre novamente o amparo da Declaração Universal dos Direitos Humanos como meio de se justificar que a pretensão das proposições da mesma é criar o ambiente plural, onde se pensa de forma global, mesmo que se considere as "famílias" como entes separados, quando ainda no preambulo leva-se em conta tal possibilidade, considerando ser essencial promover o desenvolvimento de relações amistosas entre as nações.

Como afirmado nasce do natural aspecto solidário do ser humano a fraternidade, evidentemente fruto de culturas que pressupõe que tais "famílias" de seres não 
necessariamente consanguíneos advém de uma paternidade ou maternidade comum divina, dependendo de cada crença.

\begin{abstract}
O estudo histórico da fraternidade e da solidariedade é importante para compreender-se a situação do binômio no presente, como categorias jurídicas que, por meio de processos de constitucionalizações, foram sendo internalizadas nos mais diversos ordenamentos jurídicos, mas acima de tudo, para ressaltar que ainda permanecem como desafios, no presente e para o futuro, no ainda não concluso processo de resgate do vínculo antropológico comum dos seres humanos, o que contribuirá essencialmente para a superação das crises existentes nas sociedades do presente século. (BORGES; BESTER, 2017, p. 93)
\end{abstract}

Morin já trazia até como necessidade vital, quando ensinava que em nosso mundo de homens, no qual as forças de separação, recolhimento, ruptura, deslocamento, ódio, são cada vez mais poderosas, mais do que sonhar com a harmonia geral ou com o paraíso, devemos reconhecer a "necessidade vital, social e ética de amizade, de afeição e de amor pelos seres humanos, os quais, sem isso, viveriam de hostilidade e de agressividade, tornando-se amargos ou perecendo." (MORIN, 2005, p. 36)

A toda evidência trata-se de um desafio tendo em vista que a própria sociedade afasta o pensamento e o comportamento solidário, como analisa Bauman a grande maioria das pessoas, por mais que sua crenças e intenções sejam nobres e elevadas, se vê confrontada com realidades hostis, vingativas e acima de tudo indômitas; realidade de cobiça, corrupção, rivalidade e egoísmo onipresentes de todos os lados, e, por isso mesmo, realidade que aconselham e exaltam a desconfiança recíproca e a vigilância perpétua.” (BAUMAN, 2015, p. 37)

Ulrick Beck traz uma certa pacificação consubstanciada na inação em razão da própria impossibilidade de se apurar uma conclusão. Essa tendência à globalização faz surgir suscetibilidades, que são por sua vez inespecíficas em sua universalidade. Quando tudo se converte em ameaça, de certa forma nada mais é perigoso. Quando já não há saída, o melhor afinal é não pensar mais na questão. $\mathrm{O}$ fatalismo ecológico do fim dos tempos faz o pêndulo dos ânimos oscilar em todas as direções. Agir é de todo modo algo ultrapassado. Talvez os ubíquos e perenes pesticidas possam ser contornados com o retorno dos insetos, ou com uma taça de champanhe? (BECK, 2015, p. 44)

Assim, há que se perceber que a realidade afasta a aceitação da natureza humana da solidariedade, entretanto está sempre é resgatada quando se busca tecer conceitos sobre a essência do próprio ser. 
Ferreira Filho, traça as linhas sobre os direitos fundamentais e apresenta como sendo um novo direito fundamental o direito de solidariedade, ensinando que o reconhecimento dos direitos sociais não pôs termo à ampliação do campo dos direitos fundamentais. Na verdade, a consciência de novos desafios, não mais à vida e à liberdade, mas especialmente à qualidade de vida e à solidariedade entre os seres humanos de todas as raças ou nações, redundou no surgimento de uma nova geração - a terceira - a dos direitos fundamentais. (FERREIRA FILHO, 2012, p. 75)

A solidariedade apresentada como natural, e enquadrada nos direitos fundamentais, tem em sua aceitação enquanto trama social necessária a própria comprovação de que advém da essência do ser humano em razão até de sua não rejeição ser natural, mas sim eventualmente fruto de desvirtuação da própria natureza humana.

Corroborando nessa premissa, Santiago elucida que dentro da sociedade, faz-se necessário que os indivíduos atuem de forma organizada e colaborem entre si, viabilizando a sobrevivência e a evolução do grupo, de onde se depreende a noção da solidariedade social. (SANTIAGO, 2017, p. 191)

Assim, consubstanciada na Constituição Federal, o Princípio da Solidariedade, tornase força motriz para alcançar o primeiro objetivo da Carta Magna, construir uma sociedade livre, justa e solidária, tendo em vista

Apresentada então como elemento e/ou condição sociocultural por consubstanciar e propiciar um ambiente favorável ao desenvolvimento, promoção e manutenção da economia compartilhada, que tem suas bases na solidariedade.

\section{CONSIDERAÇÕES FINAIS}

Ao identificar os mecanismos da solidariedade social mecânica - como um dever-ser, uma condição essencialmente natural e, principalmente, como forma de incessante busca em que pese os necessários contrapontos e as evidentes exceções - demonstra ser um ambiente mais propício para coesão social e, desta feita, para a efetivação e implementação das novas modalidades de economia compartilhada. Constatou-se que a coparticipação social abre meios para que a humanidade possa quebrar certas barreiras e valorizar outros fatores. 
Evidenciou-se que a solidariedade orgânica, em que pese ter funcionado muito bem por décadas, atualmente promove um comportamento predatório, solitário e competitivo, visto que as desigualdades sociais e a injusta divisão do trabalho, produzem formas mais intensas de individualismo, o que faz, por sua vez, a consciência coletiva perder, em parte, sua capacidade agregadora.

Acredita-se que há possibilidade de que o elemento 'solidariedade' aqui evidenciado em viés mais natural, possa ser caracterizado por um traço evolutivo, entretanto, mesmo que assim seja considerado, abre um caminho mais espontâneo ao ambiente favorável, social e culturalmente ao compartilhamento de bens e serviços.

Nesse ambiente que se observa, a construção de uma sociedade justa prevista no texto constitucional, que molda ideais de igualdade, combater à concentração de renda encontra eco, e a economia diante de exemplos emblemáticos se organiza de forma a suprir a necessidade social.

Apenas o ideal de se confrontar o paradigma, possuir $\mathrm{X}$ ter acesso, como meio de justificar iniciativas empreendedoras, e novos padrões de consumo, já semeiam o pensamento mais coletivista que pode chegar à "utopia" de que haja uma renda básica universal que possibilite dignidade a todos, permitindo que a previsão constitucional seja alcançada.

E economia compartilhada, surge nesse contexto de busca por desburocratização, de novas conexões, de efetivação da liquidez nas relações, e até a desmaterialização de valores econômicos, podem produzir uma futura sociedade onde a busca do bem comum seja a tônica envolvendo todos os atores.

Assim, o ambiente sendo favorável, a economia compartilhada sendo apresentada como resposta, e a solidariedade identificada como elemento natural abrem espaço para novas possibilidade e modalidades econômicas, que de forma algum perdem o seu caráter propriamente econômico, mas de certa forma oportunizam e incluem iniciativas que somente conseguem ser oferecidas frente à esta mudança de pensamento.

Como apresentado, as preocupações e controvérsias são válidas e precisam atuar como limitadores de abusos, afim de que a distorção de boas iniciativas não acabe por gerar mais desigualdade e concentração de renda, afastando o propósito inicial que somente permanecerá resguardado se a solidariedade não for colocada em segundo plano como 
observado neste estudo, que à apresenta como elemento natural na busca por uma sociedade mais justa e socialmente igualitária.

\section{REFERÊNCIAS BIBLIOGRÁFICAS}

BAUMAN, Zygmunt. A Riqueza de poucos beneficia todos nós? Trad. Renato Aguiar. Rio de Janeiro, Zahar Ed. 2015.

Zygmund. Vida Liquida. Trad. Carlos Alberto Medeiros. Rio de Janeiro: Jorge Zahar, 2007

, Zygmund. Modernidade Líquida. Trad. Plínio Dentzien. Rio de Janeiro, Zahar Ed. 2001.

, Zygmund. Tempos Líquidos. Trad. Carlos Alberto Medeiros. Rio de Janeiro: Jorge Zahar Ed. 2007.

BECK, Ulrich. Sociedade de Risco: rumo a outra modernidade. Trad. Sebastião Nascimento, $2^{a}$ Edição, Editora 34, São Paulo, 2011

BELK, Russel. W. You are what you can access: Sharing and collaborative consumption online. Journal of Business Research, v.67, n. 8, 2013. Disponível em:

https://www.sciencedirect.com/science/article/pii/S0148296313003366. Acesso em: 20 out. 2019

BESTER, Gisela Maria; BORGES, Nayara Gallieta. Fraternidade e a Solidariedade como Propulsoras de ativismo participativo: Afirmação da Igualdade material contra a Proibição da Discussão da Diversidade Humana de Gênero no Sistema Público escolar de Palmas/TO Estudo de Caso sobre a ADI 0011990-05.2016.827.0000/16-TJTO IN: Direito e

Solidariedade, Editora Juruá, Curitiba, 2017;

BRASIL. Constituição da República Federativa do Brasil. Disponível em: < http://www.planalto.gov.br/ccivil_03/constituicao/constituicao.htm> Acesso em: 20 out. 2019.

Tribunal Regional do Trabalho $3^{\mathrm{a}}$ Região. RTOrd. $\mathbf{n}^{\circ}$ 0011359-34.2016.5.03.0112.

Disponível em:

http://pje.trt3.jus.br/primeirograu/Processo/ConsultaDocumento/listView.seam?nd=17013114 275439000000038127039. Acesso em: 20 ago. 2019. 
BULL, Patrícia. Terreno Fértil para a Inovação. Revista da Câmara de Comércio Brasil Canadá, ano 12, número 68, Editora Casa Nova, São Paulo 2017.

CARNEIRO, Vinícius Maximiliano. Dinheiro da multidão: oportunidades x burocracia no crowdfunding nacional. 1. ed. 2014. Disponível em:

http://viniciuscarneiro.adv.br/ebooks/dinheiromultidao/dinheirodamultidao_viniciusmaximilia no.pdf?dl=1. Acesso em: 15 maio 2019.

CHASE, Robin. Economia Compartilhada: Como pessoas e plataformas da Peers Inc. estão reinventando o capitalismo. Ed. HSM, São Paulo, 2015.

DIAMANDIS, Peter H. e KOTLER, Steven. BOLD: How to go big, create wealth, and impact the world. Ed. Simon \& Schuster Paperbacks, New York, 2016.

DIAMANDIS, Peter H.; KOTLER, Steven. Abundância: O Futuro é melhor do que você imagina. Abundance: the future is better than you think. Trad. Ivo Korytowski. São Paulo: HSM, 2012

DOURADO, Patrícia. A Construção de Uma Jornada Otimista: Entre a Euforia de Maria Antonieta de Sofia Coppola. Disponível em:

https://sapientia.pucsp.br/bitstream/handle/4593/1/Patricia\%20Dourado.pdf. Acesso em: 18 ago. 2018.

DURKHEIM, Émile. Da divisão de trabalho social. 3.ed. Trad. Eduardo Brandão. São Paulo: Martins Fontes, 2008.

Educação e sociologia. 7.ed. São Paulo: Melhoramentos, 1978.

et al. Introdução ao pensamento sociológico. São Paulo: Centauro, 2001.

ELKINGTON, John. Sustentabilidade, canibais com garfo e faca. São Paulo: M.Books do Brasil Editora, 2012.

FERREIA FILHO, Manoel Gonçalves. Direitos Humanos Fundamentais. 14 a ed. Editora Saraiva: São Paulo 2012;

GANSKY, Lisa. Mesh. Porque o futuro dos negócios é compartilhar. Rio de Janeiro: Alta Books, 2011. 
MORIN, Edgar. A via para o futuro da humanidade. $2^{a}$ Edição, Tradução de Edgard de Assis Carvalho e Marisa Perassi Bosco, Rio de Janeiro, Editora Bertrand, 2015;

Edgar. O Método VI: ética. 2. Ed. Trad. Juremir Machado da Silva. Porto Alegre: Porto Alegre: Sulina, 2005.

ORGANIZAÇÃO DAS NAÇÕES UNIDADES. Declaração Universal dos Direitos Humanos. 1948. Disponível em: https://www.unicef.org/brazil/pt/resources_10133.htm. Acesso em: 20 ago. 2019.

PETRANEK, Stephen L. How We'll Live on Mars, Simon \& Schuster, New York, 2015.

RAWLS, John. Justiça e Democracia. Trad. Irene A. Peternot. São Paulo: Martins Fontes, 2000

SANTIAGO, Mariana Ribeiro. O Direito Civil sob a ótica da solidariedade social. IN: Direito e Solidariedade. Editora Juruá, Curitiba, 2017;

SANTIAGO, Mariana Ribeiro; CAMPELLO, Lívia Gaigher Bósio. O Consumo Colaborativo e Sustentável na Sociedade da Informação. In: III Encontro de Internacionalização do Conpedi, Madrid, 2015. Disponível em: http://portaltutor.com/index.php/conpedireview/article/viewFile/43/40. Acesso em: 08 jun. abr. 2019.

SHIRKY, Clay. A Cultura da Participação. Criatividade e Generosidade no mundo Conectado. Tradução Celina Portocarrero. Editora Zahar, Rio de Janeiro, 2011

SINGER, Paul. Curso de Introdução à Economia Política. $14^{a}$ Edição, São Paulo: Forense, 1993.

SOUZA. André Ricardo de. A economia solidária no Brasil: a autogestão como resposta ao desemprego. São Paulo: Contexto, 2000.

SUNDARARAJAN, Arun. The Sharing Economy The End of Employment and the Rise of Crowd-Based Capitalism. The MIT Press, Cambridge, MA, 2016.

SUPLICY, Eduardo Matarazzo. Renda Básica de Cidadania: a saída é pela porta. Cortez Editora, $7^{\text {a }}$ Ed., São Paulo 2013. 
TAPIOCA NETO, Renato Drummond. Julgamento e morte de Maria Antonieta: a última rainha da França - Parte IV, disponível em:

https://rainhastragicas.com/2013/10/17/julgamento-e-morte-de-maria-antonieta-a-ultimarainha-da-franca-parte-iv. Acesso em: 20 ago. 2019. 